\title{
Risk Identification and Evaluation of Customer Collaboration in Product Development
}

\author{
Xuefeng Zhang, Yu Yang, Jiafu Su \\ State Key Laboratory of Mechanical Transmissions, Chongqing University (China) \\ 2xf1987@.cqu.edu.cn,.ruvang@.cqu.edu.cn.jeff.su@.cqu.edu.cn
}

Received: February 2015

Accepted: June 2015

\section{Abstract:}

Purpose: The purpose of this paper is to identify risk factors that caused by customer collaboration in new product development systematically, and propose an approach to judge which risk factors are critical and catch substantial attention.

Design/methodology/approach: This study identifies risk factors according to the results of study retrieval, experts' evaluation and consultation, and case studies of enterprises in china. On this basis, an improved rough number approach is put forward to evaluate the importance of risk factors.

Findings: Firstly, classify risk factors into three aspects. Then, present a risk factor set, which include thirty-seven risk factors. At last, determine which risk factors are critical by using an improved rough number approach.

Originality/value: Considering there are few researches studying comprehensive risk factors of customer collaboration and assessing them, this paper explores a risk factor set of customer collaboration in product development stage, and proposes a novel approach, which can help to solve the problem of subjective, vague and lack of prior information of evaluation, to evaluate risk factors.

Keywords: customer collaboration, product development, risk identification, risk evaluation, improved rough number 


\section{Introduction}

Customer collaboration in product development is an approach, which can bring many advantages for the product development (Djelassi \& Decoopman, 2013) to develop new products (Büyüközkan \& Arsenyan, 2012). However, it also has considerable risks (Kausch, 2007).

Risk in this study refers to the factors that caused by customer collaboration that may lead to the failures. Currently, many researchers devoted their efforts to identifying and analyzing risk factors of CCPD(customer collaborative product development). Enkel, Kausch and Gassmann (2005) provided a detailed description of the various risks and offered advice on how to minimize them. These risks include loss of know-how, dependence on customers' view, dependence on customers' demands or personality etc. Song, Ming and Xu (2013) divided risk of customer collaboration into organization risk, capacity risk, knowledge risk, and market risk respectively. Moreover, they also listed some risk factors in these five categories. Kleinsmann, Buijs and Valkenburg (2010) deemed that knowledge integration among collaborative teams is difficult and complex, and it affect the success of collaborative new product development. Brockhoff (2003) noted that customers and employees may fight for the limited resources and allocation of property rights in the product development process. In addition, customers may devote their efforts to improving exist product to meeting their needs and expectations, not to developing a radical innovation product (Leonard, 2002). Kausch (2007) pointed out the damage of relationship between enterprises and key customers due to that the new product do not fulfill these customers' needs.

However, CCPD is a system composed of multiple elements (Yang, Guo, Yin, Wang \& Zhang, 2008). There are many risk factors and uncertainties embedded in the different components of CCPD, which may then deviate from the expectations of product development (Kausch, 2007). To our knowledge, the existing researches just propose and discuss parts of important risk factors, have not identify risk factors systematically and develop a risk factor set. In addition, different risk factors has different important, it is necessary for the firm to judge which risk factors are critical and catch substantial attention.

The purpose of this study is to identify possible risk factors that may lead to bad effects to product development, and propose an approach, which can help to solve the problem of subjective, vague and lack of prior information of evaluation, to evaluate risk factors. After proposing a perspective to classify risk factors, section 2 presents a risk factor set according to the results of case studies of enterprises in china. In section 3, the IRN approach is put forward to evaluate the importance of risk factors. There is an illustrative example followed by in section 4 . The final section concludes the paper. 


\section{Identification of Risk Factors in CCPD}

\subsection{Risk Factor Classification}

According to the common ways of risk factor identification (Eustace, Indupuru \& Hovey, 2010; Mandal, 2011), risk factor classification is a basis and premise for risk factor identification comprehensively.

This study intends to identify risk factors that embedded in the components of CCPD system. According to the definition and description about customer collaboration or integration in product development (Büyüközkan \& Arsenyan, 2012; Greer \& Lei, 2012; Lüthje, Herstatt \& Von Hippel, 2005), this study uses CCPD system, which consist of CCPD subjects, CCPD objects, CCPD environment and CCPD process, to reflect the process and content of customer collaboration.

During the process of CCPD, customers and professionals learn from each other and stimulate the group creativity through the cooperation in the activities of product development (Yang et al., 2008). Therefore, the main CCPD subjects are customers and professionals in enterprises. In order to develop an innovative product that can meet markets demand, many tasks must be completed. So this paper takes product development tasks as the objects. CCPD environment mainly embody as macro-environment, Micro-environment, and enterprise environment. CCPD process focuses on the description of information interaction and expression between customers and professionals, and resources coordination and scheduling according to the requirements of tasks (Greer \& Lei, 2012).

Based on the above analysis, we further subdivide the components of CCPD system into CCPD organization, CCPD tasks, CCPD environment, information communication and expression between customers and professionals, and tasks-resources-objects coordination and scheduling. Then, we will identify risk factors that embedded in the components of CCPD system. However, risk factors of CCPD in this paper are related to customer collaboration, the component of environment and tasks have not direct relation with the customers. So, the other three aspects are determined to classify risk factors.

\subsection{Risk Identification Methodology and Data Sample}

\section{Step 1. Study retrieval}

To provide the data basis, related studies are read extensive and in-depth summary. Keywords, such as "product innovation", "product development", "risk", "customer", "user", "collaboration", and "integration" are used to search literatures in the electronic databases (e.g., web of science, Elsevier, SpringerLink, EBSCO, Engineering Village). We also search some journals 
related to NPD and customer collaborative innovation to find relevant literatures. This search obtained 78 related manuscripts, which published between 1990 and 2013. Some literatures only discussed a risk factor and proposed the detailed measurements to minimize it. While some of the literatures reported more than one risk factor about customer integration in product development. We collect, analyze, and synthesize the risk factors that directed related to customer collaboration in product develop from these literatures. In addition, we contact 17 experts in this domain from 10 universities (e.g., Rutgers University, Mississippi State University, Chongqing University, Zhejiang University) to ask for assistance identifying relevant risk factors caused by customer collaboration in product development. Eventually we get 27 risk factors.

\section{Step 2. Investigation in the enterprises}

We collected the data for risk identification in CCPD from the Chinese enterprises. We selected 64 enterprises which have experience in customer collaborative product development, which spread across different industries and categorized into six sectors: electronics (20 firms, $31.25 \%$ ), services (17 firms, $26.56 \%$ ), auto manufacturing ( 9 firms, $14.06 \%$ ), machinery ( 8 firms, 12.50\%), Internet (6 firms, 9.38\%), food (4 firms, 6.25\%). Electronics and services firms face fierce competition and product life cycle is short. Therefore, new product development is critical for firm proceeds steadily, and customers always integration in product development process. It's also indicating that customer integration come to more general and not limited to specific industries and firms.

In the second phase, eight firms are selected for in-depth case studies. These eight firms respectively are Huawei, ZTE, Xiaomi Tech, Foxconn, Dongfeng Nissan, CCB, Postal Savings Bank of China, Tencent. They not only have experience with customer collaboration, but also pay much attention on risk identification and management. In these firms, we invited 187 employees who have participated in CCPD projects to identify risk factors that caused by customers integration. The initial questionnaire contained items taken from the results of step 1. These respondents were asked to evaluate whether risk factors in the questionnaire occurred in practice. Moreover, supplement and complete these risk factors according to their experience and the actual situations. Before sending the questionnaire, we explain the purpose of this research to respondents and confirm their willingness to participate by E-mail. After one week, we conducted reminder E-mail to encourage responses. 


\subsection{Risk Factors}

Eventually, 120 questionnaires were returned. Through collecting and analyzing the results of returned questionnaires, we obtain a total of 37 risk factors related to customer collaboration in product development. Table 1 lists these risk factors. In this table, risk factors are depicted as $\{$ Risk name, Classification\}. For example, customers' limited domain expertise, experience and knowledge $\left(O_{11}\right)$ denotes this risk factor belongs to CCPD organization. $O_{11}$ is risk factor code.

\begin{tabular}{|c|c|}
\hline Classilication & Risk factors \\
\hline $\begin{array}{c}\text { CCPD organization } \\
\text { (O) }\end{array}$ & 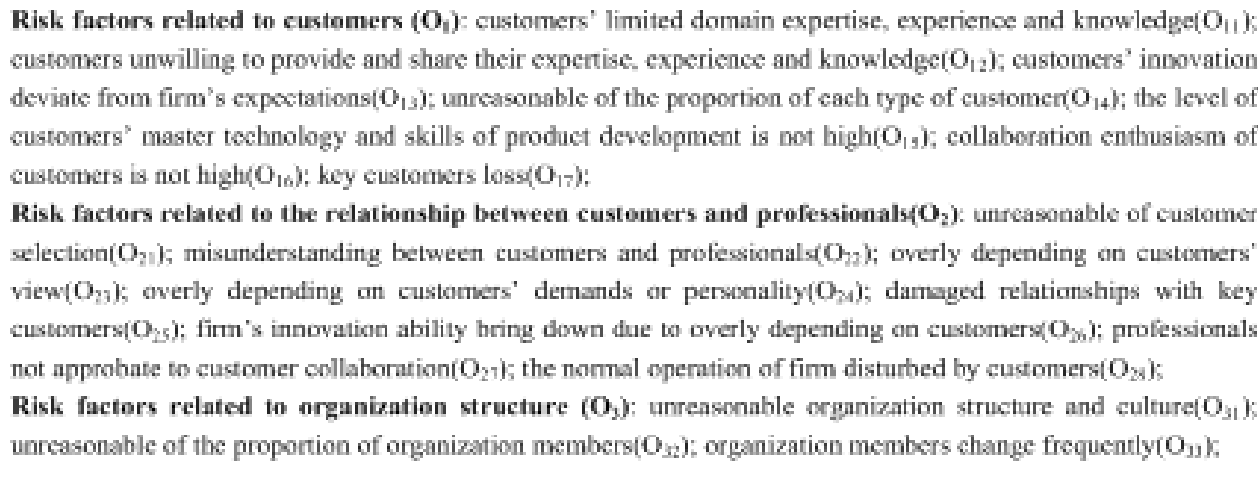 \\
\hline $\begin{array}{l}\text { Information communication } \\
\text { and expression between } \\
\text { customers and professionals } \\
\text { (C) }\end{array}$ & 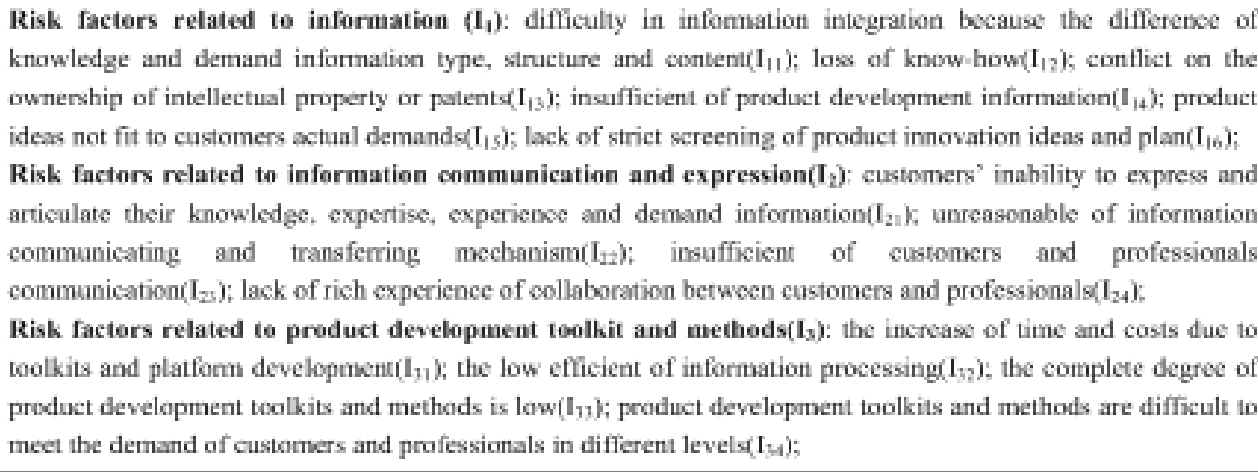 \\
\hline $\begin{array}{l}\text { Tasks-resources- } \\
\text { objects coordination } \\
\text { and scheduling } \\
\text { (T) }\end{array}$ & $\begin{array}{l}\text { Risk facters related to tasks-reseurces-ebjects ceordination and scheduling }\left(T_{1}\right) \text { : conflict for scarce } \\
\text { resources and reward }\left(T_{11}\right) \text {;infeasible of tasks allocated to customers }\left(T_{12}\right) \text {; customers expertise, experience and } \\
\left.\text { knowledge not fit to project }\left(T_{13}\right) \text {; unreasonable of timing and intensity of customer collaboration( } T_{14}\right) \text {; lack of } \\
\text { effective motivation for customers }\left(T_{15}\right) \text {; }\end{array}$ \\
\hline
\end{tabular}

Table 1. Risk factors related to customer collaboration in product development

\section{Risk Factor Evaluation}

The common methods in evaluating risk factor are divided into quantitative and qualitative approaches. Where risk probability and impact matrix (Ward \& Chapman, 2003) and risk breakdown structure (Hillson, 2003) are two qualitative methods. These qualitative methods can describe the risk probability, risk damage, risk content and the cause reason of risk. However, it cannot provide the results accurately and quantitatively. Considering these 
disadvantages of qualitative methods, enterprises prefer the quantitative methods to evaluate risk factors. The common quantitative approaches include Analytic Hierarchy Process (Zayed, Amer \& Pan, 2008), Fuzzy Analytic Hierarchy Process (Hu, Hsu, Kuo \& Wu, 2009), Bayesian Network (Chin, Tang, Yang, Wong \& Wang, 2009), monte-carlo simulation (Arunraj, Mandal \& Maiti, 2013), failure mode and effect analysis (Wu, Kefan, Gang \& Ping, 2010), TOPSIS (Tüysüz \& Kahraman, 2006) etc. It is difficult to provide accurate information for the process of constructing the comparison matrix and reflecting the vagueness of risk factors when we use Analytic Hierarchy Process to evaluate the importance of risk factors. In addition, consistency test is mass and cumbersome work. Fuzzy analytic hierarchy process and TOPSIS can deal with fuzzy information. However, a lot of sample information is needed and its collection has the certain difficulty. Bayesian network become more complex when the number of risk factors increases and requires accurate and comprehensive information from appraise subjects. It proposes high requirements for the quantity and quality of data when evaluate risk factors by monte-carlo simulation. FEMA is intuitive and easy to understand, but it is hard to obtain the accurate results.

Risk factor evaluation in CCPD is a complex subject with uncertainty. In addition, most appraise subjects evaluate these risk factors based on their experience and expertise, so their evaluation exist subjectivity and vagueness. It is essential to improve the reliability of risk factor evaluation in CCPD by avoiding the subjectivity and vagueness. Furthermore, the method in evaluating risk factors in CCPD should work well without extra information. Zhai, Khoo and Zhong (2008) proposed Rough number (RN) approach based on the concepts of domain, decision table, object attributes and coarse boundary in rough set theory. The important of risk factors are obtained by calculating the RN of risk factors, and then sort for them. The process of RN application does not require extra information and can deal with the subjectivity and vagueness of experts' evaluation. However, the number of risk factors in CCPD is quite large and the decision table of risk factors evaluation is more complex than the decision table that defined by Zhai et al. (2008). The original RN approach is used to calculate the RN and interval of boundary region of each class only, but it cannot be used to obtain the RN and interval of boundary region of each risk factor, which consists of multiple classes. Therefore, this study expands and improves RN, which defined as IRN, to evaluate the importance of risk factors.

\subsection{Determination of Rough Number of Each Risk Factor}

This study regards risk factors of CCPD as the objects and defines as $Y=\left\{Y_{1}, Y_{2}, \ldots, Y_{m}\right\} . Y_{m}$ is the $m$ th risk factor. For each risk factor, a few experts are invited to evaluate its value according to its possibility of occurrence and negative effects. $H=\left\{H_{1}, H_{2}, \ldots, H_{n}\right\}$ represents experts who evaluate the value of each risk factor. $n$ is the number of experts. 
$R=\left\{R_{1}, R_{2}, \ldots, R_{k}\right\}$ denotes the results of experts' evaluation. $R_{k}$ is the $k$ th class of an object with respect to an expert, and $R_{1}<R_{2}<\ldots<R_{k}$. Then, we propose the decision table of risk factor evaluation, as show in Table 2.

\begin{tabular}{|c|c|c|c|c|}
\hline \multirow{2}{*}{ Risk factors } & \multicolumn{4}{|c|}{ Experts } \\
\cline { 2 - 5 } & $\boldsymbol{H}_{\mathbf{1}}$ & $\boldsymbol{H}_{2}$ & $\ldots$ & $\boldsymbol{H}_{\boldsymbol{n}}$ \\
\hline$Y_{1}$ & $\ldots$ & $R_{1}$ & $\ldots$ & $\ldots$ \\
\hline$Y_{2}$ & $R_{3}$ & $R_{2}$ & $\ldots$ & $R_{k}$ \\
\hline$\ldots$ & $\ldots$ & $\ldots$ & $\ldots$ & $\ldots$ \\
\hline$Y_{k}$ & $\ldots$ & $\ldots$ & $\ldots$ & $\ldots$ \\
\hline
\end{tabular}

Table 2. The decision table of risk factor evaluation

(1) Rough number of each class

For each class $R_{s} \in R, 1 \leq s \leq k$, its upper approximation and lower approximation is:

$$
\begin{aligned}
& \overline{\operatorname{Apr}}\left(R_{s}\right)=\bigcup\left\{H \in U / R(H) \geq R_{s}\right\} \\
& \underline{\operatorname{Apr}}\left(R_{s}\right)=\bigcup\left\{H \in U / R(H) \leq R_{s}\right\}
\end{aligned}
$$

The boundary region of class $R_{\mathrm{s}}$ is:

$$
\begin{aligned}
\operatorname{Bnd}\left(R_{s}\right) & =\bigcup\left\{H \in U / R(H) \neq R_{s}\right\} \\
& =\left\{H \in U / R(H)>R_{s}\right\} \bigcup\left\{H \in U / R(H)<R_{s}\right\}
\end{aligned}
$$

The upper and lower approximation of class $R_{s}$ represents the experts who score a risk factor higher and lower than this class. The boundary region of class $R_{s}$ represents degree of vagueness. If the boundary region of class $R_{s}$ is empty, this class is precise.

Then, a rough number is used to represent class $R_{s}$ with respect to the risk factor set $Y$. It includes the upper limit $\overline{\operatorname{Lim}}\left(R_{s}\right)$ and lower $\operatorname{limit} \underline{\operatorname{Lim}}\left(R_{s}\right)$.

$$
\begin{aligned}
& \overline{\operatorname{Lim}}\left(R_{s}\right)=\frac{1}{F_{U}} \sum R(H) \mid H \in \overline{\operatorname{Apr}}\left(R_{s}\right) \\
& \underline{\operatorname{Lim}}\left(R_{s}\right)=\frac{1}{F_{L}} \sum R(H) \mid H \in \underline{\operatorname{Apr}}\left(R_{s}\right)
\end{aligned}
$$

$F_{U}$ and $F_{L}$ denote the number of objects belong to the upper approximation and lower approximation of class $R_{s}$. The upper and lower limit of class $R_{s}$ is the mean value of the classes belongs to its upper approximation and lower approximation. In this way, we transform the crisp value of experts' evaluation into the rough value, which is represented by the upper approximation $\overline{\operatorname{Lim}}\left(R_{s}\right)$ and the lower approximation $\underline{\operatorname{Lim}}\left(R_{s}\right)$. 
The RN and interval of boundary region of class $R_{s}$ are presented based on the lower and upper limit.

$$
R N\left(R_{s}\right)=\left\lfloor\underline{\operatorname{Lim}}\left(R_{s}\right), \overline{\operatorname{Lim}}\left(R_{s}\right) 7 ; \operatorname{RBnd}\left(R_{s}\right)=\overline{\operatorname{Lim}}\left(R_{s}\right)-\underline{\operatorname{Lim}}\left(R_{s}\right)\right.
$$

The rough number and interval of boundary region represent the subjective judgment and preference of experts. The interval of boundary region reflects the degree of inaccuracy. The greater the interval of boundary region of a class rough number, the less precise of it.

(2) Rough number of each risk factor

After calculating the RN and interval of boundary region of each class based on the above analysis, we determine the lower limit, upper limit, RN and interval of boundary region of each risk factor by solving the average of the above aspects of all classes. The upper and lower limit of risk factor $Y_{i}$ is:

$$
\overline{\operatorname{Lim}}\left(Y_{i}\right)=\frac{1}{n} \sum_{s=1}^{k} \overline{\operatorname{Lim}}\left(R_{s}\right) ; \underline{\operatorname{Lim}}\left(Y_{i}\right)=\frac{1}{n} \sum_{s=1}^{k} \underline{\operatorname{Lim}}\left(R_{s}\right)
$$

The RN and interval of boundary region of risk factor $Y_{i}$ are:

$$
\begin{aligned}
& R N\left(Y_{i}\right)=\left\lfloor\underline{\operatorname{Lim}}\left(Y_{i}\right), \overline{\operatorname{Lim}}\left(Y_{i}\right)\right\rceil \\
& \operatorname{Bnd}\left(Y_{i}\right)=\overline{\operatorname{Lim}}\left(Y_{i}\right)-\underline{\operatorname{Lim}}\left(Y_{i}\right)
\end{aligned}
$$

It can be seen from the above analysis that there are two differences between RN and IRN. Firstly, Zhai et al. (2008) defined the decision table only part of the decision table depicted in Table 2. Secondly, the original RN approach only used to calculate the RN and interval of boundary region of each class, but it cannot used to obtain the RN and interval of boundary region of each risk factor, which consists of multiple classes.

\subsection{Determination of the Importance of Each Risk Factor}

According to its RN and interval of boundary region of risk factor, we can determine the importance of each risk factor. On this basis, there are two steps to rank the priorities of risk factors.

Step 1. Determine the average of RN of each risk factor.

$$
M\left(Y_{i}\right)=\frac{\operatorname{Lim}\left(Y_{i}\right)+\overline{\operatorname{Lim}}\left(Y_{i}\right)}{2}
$$


Step 2. Compare the lower limit, upper limit and RN of each risk factor.

Take two risk factors $Y_{1}$ and $Y_{2}$ as an example. If the average of RN of $Y_{1}$ and $Y_{2}$ is equal, i.e. $M\left(Y_{1}\right)=M\left(Y_{2}\right)$, then we compare the interval of boundary region of these two risk factors. If $\operatorname{Bnd}\left(Y_{1}\right)>\operatorname{Bnd}\left(Y_{2}\right)$, risk factor $Y_{2}$ is more important than risk factor $Y_{1}$. On the contrary, risk factor $Y_{1}$ is more important than risk factor $Y_{2}$. If $M\left(Y_{1}\right)>M\left(Y_{2}\right)$, risk factor $Y_{1}$ is more important than risk factor $Y_{2}$. Otherwise, risk factor $Y_{2}$ is more important than risk factor $Y_{1}$. If $M\left(Y_{1}\right)=M\left(Y_{2}\right)$ and $B n d\left(Y_{1}\right)=B n d\left(Y_{2}\right)$, risk factor $Y_{1}$ and $Y_{2}$ have the same importance. According to the above three principles, the priority of risk factors can be established through compared in pairs.

\section{Case Study}

This section presents a mobile phone design case to illustrate how the proposed method is applied to risk factor evaluation.

\subsection{Risk Factors in the Mobile Phone Development}

According to the results in section 2 and section 3, the firm invites ten experts (include experts in this field, customers and employees) to identify risk factors of customer collaboration in the process of mobile phone development by investigating the tasks of customers' undertake and interviewing with other employees who participate in this project. Finally, risk factors of unreasonable organization structure and culture, unreasonable of the proportion of organization members, the increase of time and costs due to toolkits and platform development, and the complete degree of product development toolkits and methods is low in the Table 1 are not occur in the this mobile phone development project. The others risk factors see in Table 1.

For these risk factors, ten experts evaluate its possibility of occurrence and negative effects according to the actual situations. Five point Likert scale is used to measure the possibility of occurrence, as shown in Table 3. The evaluation value of the negative effects of each risk factor is similar to this.

\begin{tabular}{|c|c|c|c|c|c|}
\hline $\begin{array}{c}\text { The possibility of } \\
\text { risk occurrence }\end{array}$ & $\begin{array}{c}\text { Greater } \\
\text { possibility }\end{array}$ & $\begin{array}{c}\text { Great } \\
\text { possibility }\end{array}$ & Possibility & $\begin{array}{c}\text { Small } \\
\text { possibility }\end{array}$ & $\begin{array}{c}\text { Smaller } \\
\text { possibility }\end{array}$ \\
\hline Evaluation value & 5 & 4 & 3 & 2 & 1 \\
\hline
\end{tabular}

Table 3. The five point Likert scale for measuring the possibility of risk factor occurrence 
According to the above analysis, the evaluation value of each risk factor evaluated by each expert can be obtained, as shown in Table 4. $\left\{H_{1}, H_{2}, \ldots, H_{10}\right\}$ represents the ten experts.

\begin{tabular}{|c|c|c|c|c|c|c|c|c|c|c|c|c|}
\hline & $\boldsymbol{O}_{11}$ & $\boldsymbol{O}_{12}$ & $\ldots$ & $\boldsymbol{I}_{11}$ & $\boldsymbol{I}_{\mathbf{1 4}}$ & $\ldots$ & $\boldsymbol{I}_{\mathbf{3 3}}$ & $\boldsymbol{I}_{\mathbf{3 4}}$ & $\ldots$ & $\boldsymbol{T}_{\mathbf{1 3}}$ & $\boldsymbol{T}_{\mathbf{1 4}}$ & $\boldsymbol{T}_{\mathbf{1 5}}$ \\
\hline $\boldsymbol{H}_{\mathbf{1}}$ & 20 & 16 & $\ldots$ & 10 & 15 & $\ldots$ & 10 & 12 & $\ldots$ & 12 & 10 & 16 \\
\hline $\boldsymbol{H}_{\mathbf{2}}$ & 16 & 16 & $\ldots$ & 20 & 9 & $\ldots$ & 9 & 10 & $\ldots$ & 15 & 6 & 12 \\
\hline $\boldsymbol{H}_{\mathbf{3}}$ & 12 & 20 & $\ldots$ & 12 & 8 & $\ldots$ & 9 & 10 & $\ldots$ & 10 & 9 & 16 \\
\hline$\ldots$ & $\ldots$ & $\ldots$ & $\ldots$ & $\ldots$ & $\ldots$ & $\ldots$ & $\ldots$ & $\ldots$ & $\ldots$ & $\ldots$ & $\ldots$ & $\ldots$ \\
\hline $\boldsymbol{H}_{9}$ & 15 & 16 & $\ldots$ & 20 & 10 & $\ldots$ & 10 & 8 & $\ldots$ & 12 & 5 & 16 \\
\hline $\boldsymbol{H}_{\mathbf{1 0}}$ & 20 & 16 & $\ldots$ & 15 & 6 & $\ldots$ & 6 & 8 & $\ldots$ & 8 & 10 & 20 \\
\hline
\end{tabular}

Table 4. The evaluation value of each risk factor

\subsection{Evaluation of the Importance of Risk Factor}

For example, for the risk customers' limited domain expertise, experience and knowledge $\left(O_{11}\right)$, there are eight classes of its evaluation and their order is $6<8<9<10<12<15<16<20$. According to Equations (1)-(4), we calculate the lower and upper approximation, the lower and upper limit, rough number and interval of boundary region of each class as follow:

$$
\begin{aligned}
& \overline{\operatorname{Apr}}(15)=\left\{H_{1}, H_{2}, H_{5}, H_{9}, H_{10}\right\} \\
& \underline{\operatorname{Apr}}(15)=\left\{H_{3}, H_{4}, H_{5}, H_{6}, H_{7}, H_{8}, H_{9}\right\} \\
& \overline{\operatorname{Lim}}(15)=\frac{1}{5}(20 \times 2+16+15 \times 2)=17.20 \\
& \underline{\operatorname{Lim}}(15)=\frac{1}{7}(15 \times 2+12+10+9+8+6)=10.71 \\
& R B n d(15)=\overline{\operatorname{Lim}}(15)-\underline{\operatorname{Lim}}(15)=17.20-10.71=6.49 R N(15)=\lfloor\underline{\operatorname{Lim}}(15), \overline{\operatorname{Lim}}(15)\rceil=\lfloor 10.71,17.20\rceil
\end{aligned}
$$

In the same way, the other classes of risk factor customers' limited domain expertise, experience and knowledge $\left(O_{11}\right)$ can be obtained. According to the result of each class of risk factor $O_{11}$, the lower limit, upper limit, RN and interval of boundary region of this risk factor are calculated as: 


$$
\begin{gathered}
\overline{\operatorname{Lim}}\left(O_{11}\right)=\frac{1}{10}(\overline{\operatorname{Lim}}(6)+\overline{\operatorname{Lim}}(8)+\overline{\operatorname{Lim}}(9)+\overline{\operatorname{Lim}}(10)+\overline{\operatorname{Lim}}(12) \\
+\overline{\operatorname{Lim}}(15) \times 2+\overline{\operatorname{Lim}}(16)+\overline{\operatorname{Lim}}(20) \times 2)=15.26 \\
\underline{\operatorname{Lim}}\left(O_{11}\right)=\frac{1}{10}(\underline{\operatorname{Lim}}(6)+\underline{\operatorname{Lim}}(8)+\underline{\operatorname{Lim}}(9)+\underline{\operatorname{Lim}}(10)+\underline{\operatorname{Lim}}(12) \\
+\underline{\operatorname{Lim}}(15) \times 2+\underline{\operatorname{Lim}}(16)+\underline{\operatorname{Lim}}(20) \times 2)=9.69 \\
\left.\operatorname{RBnd}\left(O_{11}\right)=\overline{\operatorname{Lim}}\left(O_{11}\right)-\underline{\operatorname{Lim}}\left(O_{11}\right)=5.57 \quad \quad \operatorname{RN}\left(O_{11}\right)=\underline{L} \underline{\operatorname{Lim}}\left(O_{11}\right), \overline{\operatorname{Lim}}\left(O_{11}\right)\right]=\lfloor 9.69,15.267 \\
M\left(O_{11}\right)=\frac{\operatorname{Lim}\left(O_{11}\right)+\overline{\operatorname{Lim}}\left(O_{11}\right)}{2}=\frac{9.69+15.26}{2}=12.48
\end{gathered}
$$

\begin{tabular}{|c|c|c|c|c|c|c|c|}
\hline $\begin{array}{l}\text { Risk } \\
\text { factor }\end{array}$ & $R N$ & RBnd & $M$ & $\begin{array}{l}\text { Risk } \\
\text { factor }\end{array}$ & $R N$ & RBnd & $M$ \\
\hline$O_{11}$ & $\lceil 15.26,9.69\rfloor$ & 5.57 & 12.48 & $I_{13}$ & $\lceil 14.37,9.89\rfloor$ & 4.48 & 12.13 \\
\hline$O_{12}$ & $\lceil 16.38,12.20\rfloor$ & 4.18 & 14.29 & $I_{14}$ & $\lceil 13.18,8.30\rfloor$ & 4.88 & 10.74 \\
\hline$O_{13}$ & $\lceil 12.89,8.37\rfloor$ & 4.52 & 10.63 & $I_{15}$ & $\lceil 14.16,9.68\rfloor$ & 4.48 & 11.92 \\
\hline$O_{14}$ & $\lceil 14.18,9.68\rfloor$ & 4.50 & 11.93 & $I_{16}$ & $\lceil 13.64,9.22\rfloor$ & 4.42 & 11.43 \\
\hline$O_{15}$ & $\lceil 15.34,9.56\rfloor$ & 5.78 & 12.45 & $I_{21}$ & $\lceil 15.44,9.20\rfloor$ & 6.24 & 12.32 \\
\hline$O_{16}$ & $\lceil 14.01,9.57\rfloor$ & 4.44 & 11.79 & $I_{22}$ & $\lceil 14.39,9.91\rfloor$ & 4.48 & 12.15 \\
\hline$O_{17}$ & $\lceil 15.87,10.31\rfloor$ & 5.56 & 13.09 & $I_{23}$ & $\lceil 15.54,9.10\rfloor$ & 6.44 & 12.32 \\
\hline$O_{21}$ & [14.01,9.57 & 4.44 & 11.79 & $I_{24}$ & $\lceil 15.57,9.13\rfloor$ & 6.44 & 12.35 \\
\hline $\mathrm{O}_{22}$ & $\lceil 16.73,12.01\rfloor$ & 4.72 & 14.37 & $I_{32}$ & $\lceil 14.35,9.91\rfloor$ & 4.44 & 12.13 \\
\hline $\mathrm{O}_{23}$ & $\lceil 16.38,12.20\rfloor$ & 4.18 & 14.29 & $I_{33}$ & $\lceil 13.31,8.95\rfloor$ & 4.36 & 11.13 \\
\hline $\mathrm{O}_{24}$ & $\lceil 16.08,11.66\rfloor$ & 4.42 & 13.87 & $I_{34}$ & $\lceil 13.47,8.89\rfloor$ & 4.58 & 11.18 \\
\hline $\mathrm{O}_{26}$ & $\lceil 14.09,9.49\rfloor$ & 4.60 & 11.79 & $T_{11}$ & {$[14.39,10.01\rfloor$} & 4.38 & 12.20 \\
\hline $\mathrm{O}_{27}$ & $\lceil 14.21,9.93\rfloor$ & 4.28 & 12.07 & $T_{12}$ & $\lceil 13.31,8.83\rfloor$ & 4.48 & 11.07 \\
\hline $\mathrm{O}_{28}$ & {$[15.57,9.13\rfloor$} & 6.44 & 12.35 & $T_{13}$ & $\lceil 14.28,9.98\rfloor$ & 4.30 & 12.13 \\
\hline $\mathrm{O}_{33}$ & $\lceil 13.21,8.27\rfloor$ & 4.94 & 10.74 & $T_{14}$ & $\lceil 13.24,8.34\rfloor$ & 4.90 & 10.79 \\
\hline$I_{11}$ & $\lceil 14.09,9.63\rfloor$ & 4.46 & 11.86 & $T_{15}$ & $\lceil 13.88,9.28\rfloor$ & 4.60 & 11.58 \\
\hline$I_{12}$ & $\lceil 16.86,12.13\rfloor$ & 4.73 & 14.50 & & & & \\
\hline
\end{tabular}

Then we calculate the lower limit, upper limit, RN and interval of boundary region of other risks. The results as show in Table 5.

Table 5. The results of risk factor evaluation

It can be seen that the top five risk factors are loss of know-how, misunderstanding between customers and professionals, overly depending on customers' view, customers unwilling to 
provide and share their expertise, experience and knowledge, overly depending on customers' demands or personality, key customers churn. These five risk factors are caused by customers themselves. To a certain extent, the results of risk factor evaluation demonstrate the conclusions drew by Enkel et al. (2005) and Kausch (2007) from the perspective of quantitative.

In allusion to these five risk factors, it is important for enterprises to take some measurements to prevent and control them. There mainly are four measurements could be used. Firstly, select the right customers. According to the demand of product development, the firm should considerate carefully the knowledge, expertise, experience, skills, and attitude of different customers. Those customers who well-suited for product development, are selected to collaborate. Secondly, divide customers into different type. For those important customers, such as lead users, their views are critical for product development relative to the normal customers. Distinguishing customers is an important measurement to avoid the risk factor of overly depending on customers' view, demands, and personality. Thirdly, make the proper incentive plan. The proper incentive plan can contribute to encourage customers share, communicate, and exchange information and knowledge with professionals. Also, it is help to the firm to keep a stable cooperative relationship with customers. Fourthly, establish the right moment and right task for customer collaboration. This is not only promotes customers to play the great role in the product development process, but also help to prevent risk factor of loss of know-how.

Based on the above analysis, we summarize the characteristics of IRN approach to evaluate the importance of risk factors of customer collaboration in product development.

1. IRN approach can work well when the number of risk factors is large. In this study, there are 37 risk factors, AHP, Fuzzy AHP, Fuzzy group AHP, and fuzzy extended AHP approach are cannot function well, because the way of constructing the pair-wise comparison matrix between these risk factors is infeasible. In addition, it is too hard for experts to judge so many pair-wise comparison matrixes, and the conflict and inconsistency will be occurring easily.

2. The RN and interval of boundary of region of a risk factor not only reflect the importance of this risk factor, but also represents the consistency of experts' evaluation. For example, the normal operation of firm disturbed by customers $\left(\mathrm{O}_{28}\right)$, the importance of this risk factor is medium. However, the interval of boundary of region of this risk factor is large (6.44), which represents there is a great difference between experts' evaluation on it. IRN approach is more practical and can reflect more information than the approaches, which only get the value of the importance of risk factors, such as the approach of averaged experts' evaluation scores directly. 
3. Risk factor evaluation with IRN is flexible. This is because the interval of boundary of region can be adjusted based on the inherent subjectivity of experts' evaluation, and the distribution of experts' judgments is considered holistically in the process of getting the scores in the interval of boundary of region. Like approach Fuzzy group AHP, which need determine membership function beforehand, not reflect the dynamic of experts' evaluation.

\section{Conclusion}

In order to identify risk factors comprehensively, we analyzed the components of CCPD system, and classified risk factors into three aspects. Then, we propose a risk factor set, which includes 37 risk factors, based on the study retrieval, experts' evaluation and consultation, and investigation in the Chinese enterprises. A novel approach of IRN is proposed to evaluate risk factors. This approach can well deal with the subjectivity and vagueness of expert's evaluation. It also can avoid relying much on priori information. The risk evaluation in the case of customer collaboration in the mobile phone development shows that this approach is easy to use, and it's efficient and effective, even though the number of risk factors is large.

\section{References}

Arunraj, N., Mandal, S., \& Maiti, J. (2013). Modeling uncertainty in risk assessment: an integrated approach with fuzzy set theory and Monte Carlo simulation. Accident Analysis \& Prevention, 55, 242-255. http://dx.doi.org/10.1016/j.aap.2013.03.007

Büyüközkan, G., \& Arsenyan, J. (2012). Collaborative product development: a literature overview. Production Planning \& Control, 23(1), 47-66.

http://dx.doi.org/10.1080/09537287.2010.543169

Brockhoff, K. (2003). Customers' perspectives of involvement in new product development. International Journal of Technology Management, 26(5), 464-481.

http://dx.doi.org/10.1504/IJTM.2003.003418

Chin, K.-S., Tang, D.-W., Yang, J.-B., Wong, S.Y., \& Wang, H. (2009). Assessing new product development project risk by Bayesian network with a systematic probability generation methodology. Expert Systems with Applications, 36(6), 9879-9890.

http://dx.doi.org/10.1016/j.eswa.2009.02.019

Djelassi, S., \& Decoopman, I. (2013). Customers' participation in product development through crowdsourcing: issues and implications. Industrial Marketing Management, 42(5), 683-692. http://dx.doi.org/10.1016/j.indmarman.2013.05.006 
Enkel, E., Kausch, C., \& Gassmann, O. (2005). Managing the risk of customer integration. European Management Journal, 23(2), 203-213. http://dx.doi.org/10.1016/j.emj.2005.02.005

Eustace, D., Indupuru, V.K., \& Hovey, P. (2010). Identification of risk factors associated with motorcycle-related fatalities in Ohio. Journal of Transportation Engineering, 137(7), 474-480. http://dx.doi.org/10.1061/(ASCE)TE.1943-5436.0000229

Greer, C.R., \& Lei, D. (2012). Collaborative innovation with customers: a review of the literature and suggestions for future research. International Journal of Management Reviews, 14(1), 63-84. http://dx.doi.org/10.1111/j.1468-2370.2011.00310.x

Hillson, D. (2003). Using a risk breakdown structure in project management. Journal of Facilities Management, 2(1), 85-97. http://dx.doi.org/10.1108/14725960410808131

Hu, A.H., Hsu, C.-W., Kuo, T.-C., \& Wu, W.-C. (2009). Risk evaluation of green components to hazardous substance using FMEA and FAHP. Expert Systems with Applications, 36(3), 7142-7147. http://dx.doi.org/10.1016/j.eswa.2008.08.031

Kausch, C. (2007). A risk-benefit perspective on early customer integration. Springer, US, 51-55.

Kleinsmann, M., Buijs, J., \& Valkenburg, R. (2010). Understanding the complexity of knowledge integration in collaborative new product development teams: a case study. Journal of Engineering and Technology Management, 27(1), 20-32.

http://dx.doi.org/10.1016/j.jengtecman.2010.03.003

Lüthje, C., Herstatt, C., \& Von Hippel, E. (2005). User-innovators and "local" information: The case of mountain biking. Research Policy, 34(6), 951-965. http://dx.doi.org/10.1016/j.respol.2005.05.005

Leonard, D. (2002). The limitations of listening. Harvard Business Review, 80(1), 93.

Mandal, S. (2011). Supply chain risk identification and elimination: a theoretical perspective. The IUP Journal of Supply Chain Management, 8(1), 68-86.

Song, W., Ming, X., \& Xu, Z. (2013). Risk evaluation of customer integration in new product development under uncertainty. Computers \& Industrial Engineering, 65(3), 402-412. http://dx.doi.org/10.1016/j.cie.2013.04.001

Tüysüz, F., \& Kahraman, C. (2006). Project risk evaluation using a fuzzy analytic hierarchy process: an application to information technology projects. International Journal of Intelligent Systems, 21(6), 559-584. http://dx.doi.org/10.1002/int.20148 
Ward, S., \& Chapman, C. (2003). Transforming project risk management into project uncertainty management. International Journal of Project Management, 21(2), 97-105. http://dx.doi.org/10.1016/S0263-7863(01)00080-1

Wu, D.D., Kefan, X., Gang, C., \& Ping, G. (2010). A risk analysis model in concurrent engineering product development. Risk Analysis, 30(9), 1440-1453.

http://dx.doi.org/10.1111/j.1539-6924.2010.01432.x

Yang, Y., Guo, B., Yin, S., Wang, W.-I., \& Zhang, X.-D. (2008). Connotation, theory framework and application of customer collaborative innovation. Computer Integrated Manufacturing Systems, 14(5), 944-950.

Zayed, T., Amer, M., \& Pan, J. (2008). Assessing risk and uncertainty inherent in Chinese highway projects using AHP. International Journal of Project Management, 26(4), 408-419. http://dx.doi.org/10.1016/j.ijproman.2007.05.012

Zhai, L.-Y., Khoo, L.-P., \& Zhong, Z.-W. (2008). A rough set enhanced fuzzy approach to quality function deployment. The International Journal of Advanced Manufacturing Technology, 37(5-6), 613-624. http://dx.doi.org/10.1007/s00170-007-0989-9

Journal of Industrial Engineering and Management, 2015 (www.jiem.org) 